\title{
Research on Cross-line Train Graph Technology based on the Network operation
}

\author{
Hao Qingsheng ${ }^{1}$ Liang Hongyu ${ }^{2}$ Teng chunguang ${ }^{3}$ \\ (Beijing Traffic Control Technology Co., Ltd. Beijing 100070)
}

\begin{abstract}
Key Words: Network operating; Cross-line; Train Graph; Train operation
Abstract: Based on the single-line train graph editing, this paper proposes a cross-line editing train graph technology of the network operating. Firstly, according to the operation line parameters, determine the cross line site and the relation of each line; Secondly, according to the operation requirements of the line and the in and out station data of the each line AFC, the time of train crossing and entering is calculated. Thirdly, make a cross-line train graph with the data that has been analyzed, and finally, the train graph of each line is compiled based on the cross-line train graph.
\end{abstract}

\section{Development Overview}

With the rapid development of urban rail transit and the increasing passenger flow, it brings great challenge to Metro train transportation capability and passenger travel convenience, in the subway line connectivity technology application and network under the high speed development of prophase, the cross line operating technology based on network is imperative, cross line operation is a new kind of operation technology, is in urban rail transit network train by linking different line link, from the line running across the line to the adjacent lines, so as to realize the cross line of trains on different lines

Cross-line operations applicable conditions 1 ) The track is identical between lines, there is a contact line between the lines and the cohesion must be on the same plane; 2 ) signaling systems need to be interconnected, that is, different manufacturer signaling system through the standard interface to achieve the interconnection between different signal devices.

At present, rail transit is a single line operation mode to organize train operation, but in the trans-line operation mode, the conventional single track diagram editor has not satisfied the network operation demand, mainly manifests in the single line Train graph Editor only supports edits this route the movement diagram, each line's train graph does not have any relations, Cannot meet the interconnection of the proposed trans-line operation requirements, the current use of a single train graph to operate, the exposed problems are: Transfer station train to hair disorder, resulting in the transfer network system operating efficiency is not high, passenger transfer time is long, network local point of transportation and supply and demand of the rapid spread of network congestion caused by fast transmission of security risks.

In order to meet the requirements of line-crossing operation, the Editing of the cross line train graph is also put on the agenda. In Chongqing, the interconnection system has been widely used. In this paper, a method of editing a network-spanning train graph is proposed based on the research of the drawing method of the cross-line train graph.

The network-based cross line diagram editing method can bring the following benefits:

1) Trains are run across lines, and passengers can reach destinations, reduce the number of transfers and improve travel efficiency.

2) Reasonable dispatch of each line of vehicles, so that the reasonable use of each line, to alleviate the local point of the emergence of demand for the rapid changes in the security risks; 


\section{Principles}

The principle of implementation is as follows:

1) laying out the schematic diagram of each line, and inputting the line operation parameters, such as the number of train group, the minimum running interval of the line, the first end of the car time, the information of the intersection, etc.

2) based on determined cross-line information to enter line-crossing parameters, such as cross-line routing, cross-line stations, cross-line times, and the number of trains running on cross-line;

3) based on the related parameters of cross-line operations, editing cross line train graph, and stores it in the database;

4) to edit a single line of train graphs based on a cross-line train graph; in which, cross-line train graph and single train graph separate editing, in the single line of the train graph editing, cannot modify the cross-line train graph;

5) edits all train graphs and conflict checks when all single line runs are complete;

6) After the check is complete, the database is stored.

\section{Implementation}

to Figure 1 Road Map As an example, the method of editing the cross-line train graph is explained:

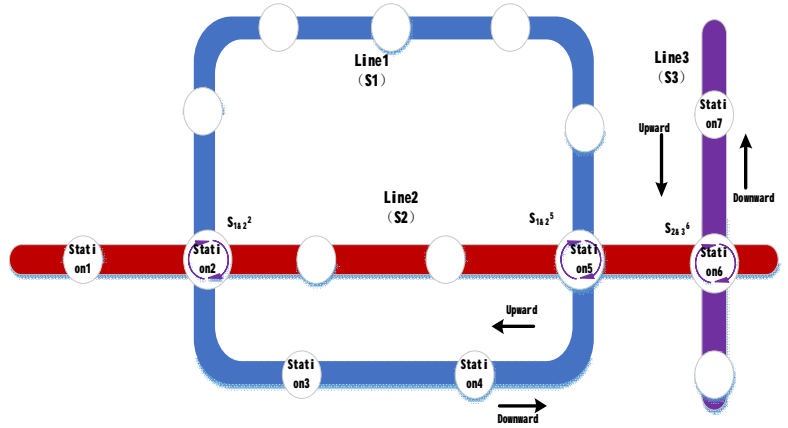

Figure 1 schematic diagram of the line

Description:

1) from right to left, top to bottom is upward direction, from left to right, down to top is downward direction, as in Figure 1 ;

2) the line 1(S1) for loop, the transfer station with line $2(\mathrm{~S} 2)$ is the station 2 and the station 5 ;

3) line 2(S2), line 3( S3) is a straight line and the transfer station is the station 6 ;

\section{To determine the line scheme}

According to the physical characteristics of each line and operational data, the relationship between the lines, such as the following table:

Table 1 line relationship

\begin{tabular}{|l|c|c|c|}
\hline & Line 1 & Line 2 & Line 3 \\
\hline $\begin{array}{l}\text { Line } \\
1\end{array}$ & - & $\mathrm{Y}$ & $\mathrm{N}$ \\
\hline $\begin{array}{l}\text { Line } \\
2\end{array}$ & $\mathrm{Y}$ & - & $\mathrm{Y}$ \\
\hline $\begin{array}{l}\text { Line } \\
3\end{array}$ & $\mathrm{~N}$ & $\mathrm{Y}$ & - \\
\hline
\end{tabular}


which:

$\mathrm{S} 1 \& \mathrm{~S} 2=\mathrm{S}_{1 \& 2^{2}} \mathrm{~S}_{1 \& 2}^{5}$; the cross-line station of line 1 and line 2 is station $2\left(\mathrm{~S}_{1 \& 2^{2}}{ }^{2}\right)$ and stations $5\left(\mathrm{~S}_{1 \& 2}{ }^{5}\right)$;

$\mathrm{S} 2 \& \mathrm{~S} 3=\mathrm{S}_{2 \& 3}{ }^{6}$; the cross-line station of line 2 and line 3 is station $26\left(\mathrm{~S}_{2 \& 3}{ }^{6}\right)$.

\section{Determine cross-line routing}

According to the relationship of the line network, the cross-line routing are determined as follows:

Table 2 line routing

\begin{tabular}{|c|c|c|}
\hline \multicolumn{3}{|c|}{ lable 2 line routing } \\
\hline & upward & downward \\
\hline Routing 1 & $\begin{array}{ll}\text { Station1-> } & \text { Station } \\
\left.2\left(\mathrm{~S}_{1 \& 2}\right)^{2}\right)> & \text { Station } \\
3 & \end{array}$ & $\begin{array}{l}\text { Station 3-> Station } \\
2\left(\mathrm{~S}_{\left.1 \& 2^{2}\right)->\text { Station } 1}\right.\end{array}$ \\
\hline Routing 2 & $\begin{array}{ll}\text { Station 4-> } & \text { Station } \\
\left.5\left(\mathrm{~S}_{1 \& 2}\right)^{5}\right)-> & \text { Station } \\
6\left(\mathrm{~S}_{2 \& 3}{ }^{6}\right)-> & \text { Station } \\
7 & \end{array}$ & $\begin{array}{l}\text { Station } 7->\text { Station } \\
6\left(\mathrm{~S}_{2 \& 3^{6}}\right)^{->} \text {Station } \\
\left.5\left(\mathrm{~S}_{1 \& 2}\right)^{5}\right)->\text { Station } 4\end{array}$ \\
\hline
\end{tabular}

\section{determines the line crossing time}

According to line operation requirements and Enter and exit AFC (Automatic Fare Collection System) data of each line history, make reasonable time for stepping out and entering, such as the following table: 
Table 3 Cross-line time

\begin{tabular}{|c|c|c|c|}
\hline Station & $\begin{array}{l}\text { In and out of the } \\
\text { station }\end{array}$ & $\begin{array}{l}\text { The site } \\
\text { staion }\end{array}$ & $\begin{array}{l}\text { The next } \\
\text { station }\end{array}$ \\
\hline \multirow[b]{2}{*}{ Station 1} & Uplink & 7: 00 & $7: 10$ \\
\hline & $\begin{array}{l}\text { Uplink } \\
\text { outbound }\end{array}$ & $7: 05$ & $7: 15$ \\
\hline \multirow{4}{*}{ Station $2\left(\mathrm{~S}_{1 \& 2}{ }^{2}\right)$} & Uplink & $7: 10$ & $7: 20$ \\
\hline & $\begin{array}{l}\text { Uplink } \\
\text { outbound }\end{array}$ & $7: 15$ & $7: 25$ \\
\hline & Down pit & $7: 30$ & $7: 40$ \\
\hline & $\begin{array}{l}\text { Downlink } \\
\text { Outbound }\end{array}$ & $7: 35$ & $7: 45$ \\
\hline \multirow{4}{*}{ Station 3} & Uplink & $7: 20$ & $7: 30$ \\
\hline & $\begin{array}{l}\text { Uplink } \\
\text { outbound }\end{array}$ & $7: 25$ & $7: 35$ \\
\hline & Down pit & $7: 20$ & $7: 30$ \\
\hline & $\begin{array}{l}\text { Downlink } \\
\text { Outbound }\end{array}$ & $7: 25$ & $7: 35$ \\
\hline \multirow{4}{*}{ Station 4} & Uplink & $7: 30$ & $7: 40$ \\
\hline & $\begin{array}{l}\text { Uplink } \\
\text { outbound }\end{array}$ & $7: 35$ & $7: 45$ \\
\hline & Down pit & $7: 50$ & 8: 00 \\
\hline & $\begin{array}{l}\text { Downlink } \\
\text { Outbound }\end{array}$ & $7: 55$ & $8: 05$ \\
\hline \multirow{4}{*}{ Station $5\left(S_{1 \& 2}{ }^{5}\right)$} & Uplink & $7: 40$ & $7: 50$ \\
\hline & $\begin{array}{l}\text { Uplink } \\
\text { outbound }\end{array}$ & $7: 45$ & $7: 55$ \\
\hline & Down pit & $7: 40$ & $7: 50$ \\
\hline & $\begin{array}{l}\text { Downlink } \\
\text { Outbound }\end{array}$ & $7: 45$ & $7: 55$ \\
\hline \multirow{4}{*}{ Station $6\left(\mathrm{~S}_{2 \& 3}{ }^{6}\right)$} & Uplink & $7: 50$ & 8: 00 \\
\hline & $\begin{array}{l}\text { Uplink } \\
\text { outbound }\end{array}$ & $7: 55$ & 8: 05 \\
\hline & Down pit & $7: 30$ & $7: 40$ \\
\hline & $\begin{array}{l}\text { Downlink } \\
\text { Outbound }\end{array}$ & $7: 35$ & $7: 45$ \\
\hline \multirow{4}{*}{ Station 7} & Uplink & 8: 00 & 8: 10 \\
\hline & $\begin{array}{l}\text { Uplink } \\
\text { outbound }\end{array}$ & 8: 05 & $8: 15$ \\
\hline & Down pit & 7: 20 & $7: 30$ \\
\hline & $\begin{array}{l}\text { Downlink } \\
\text { Outbound }\end{array}$ & $7: 25$ & $7: 35$ \\
\hline
\end{tabular}




\section{Description:}

In the Table 3, in order to be concise and clear description of the operation of the cross line diagram production principle, so in the selection of in and out of the station, using a relatively simple point of the hour, in the actual mapping, should consider AFC identify with line operation requirements to confirm inbound and outbound hours.

\section{cross-line train graph editing software}

The train graph displays the following format:

1) on the train graph, there are three lines of horizontal, vertical, and slash, using the horizontal axis to represent the time and ordinate the distance;

2) The horizontal line on the train graph indicates the name of the station that is included in the crossing, and the station is represented by a thin line;

3) The vertical line halves the horizontal axis of a day and night, usually a minute line that is represented by a thin dotted line with a five-minute line, and a thick line for the hour line;

4) The Slash is the trajectory of the train running, representing the train line. The intersection of the train running line and the centerline of the station is the time of arrival, departure or passing of the train at the station. On the train diagram, the running line of the downlink train is tilted from the upper left to the right, and the running line of the uplink train is tilted from the lower left to the right side.

The line and color rules are as follows:

1) The default plan train graph is solid, the behavior is red on the line, and the behavior is green;

2) the can be configured to specify the specified color and line style for single or multiple train runs.

\section{To edit a cross-line train graph}

According to the established Line association relationship, the routing information, the cross-line time information edit the cross-line train graph, the following diagram:

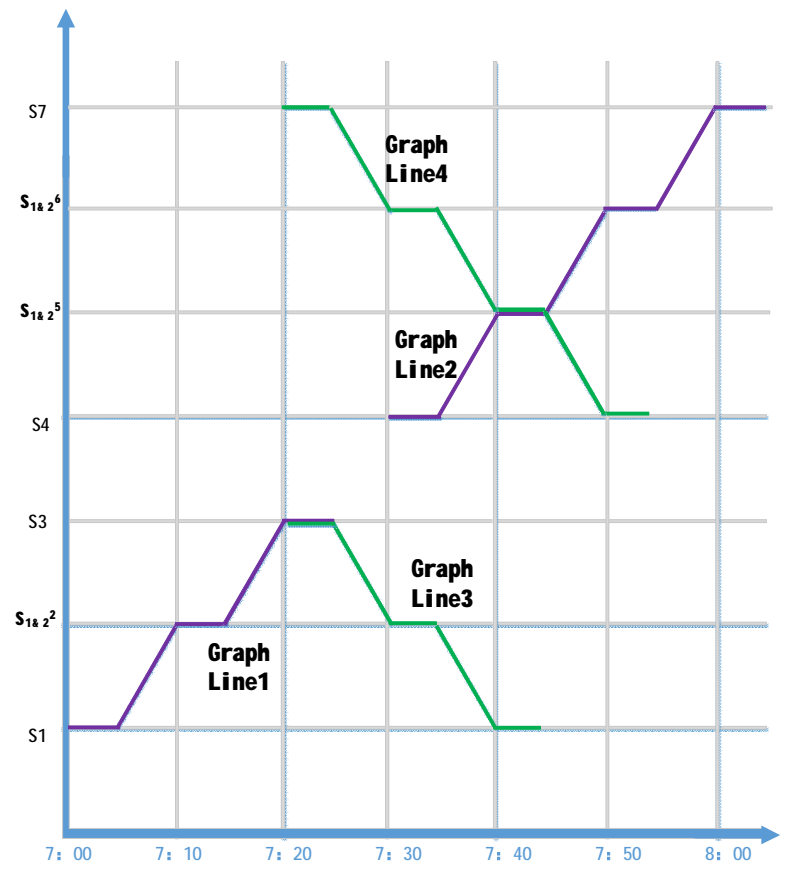

Figure 2 Cross-line Train Graph

Description:

Run lines 1 indicates train from line 1 Station 1 run down to the transfer station $2\left(\mathrm{~S}_{1 \& 2}{ }^{2}\right)$, cross-line runs to line 2 downlink, running to line 2 Station 3 ; 
Similarly: Run lines 3 indicates train from line 2 Station 3 run upstream to transfer station $2\left(\mathrm{~S}_{1 \& 2}{ }^{2}\right)$, cross-line runs to line 1 Uplink, run to line 1 Station 1 .

Run Line 2 indicates train from line 1 Station 4 run down to the transfer station $5\left(\mathrm{~S}_{1 \& 2}{ }^{5}\right)$, cross-line runs to line 2 downlink, run to transfer station $6\left(\mathrm{~S}_{2 \& 3}{ }^{6}\right)$, cross-line runs to line 3 downlink, run to line 3 Station 7 ;

Similarly, run the line 4 indicates train from line 3 Station 7 run upstream to transfer station $6\left(\mathrm{~S}_{2 \& 3}{ }^{6}\right)$, cross-line runs to line 2 uplink, run to transfer station $5\left(\mathrm{~S}_{1 \& 2}{ }^{5}\right)$, cross-line runs to line 1 Uplink, run to line 1 Station 4 .

\section{Editing a single train graph}

The train graph of each line is edited based on the cross-line train graph. When you create a new line train graph, the graph system will detect whether the line has a cross-line train graph, if there is, it is suggested that the mapping staff need to link the cross-line train graph, if necessary, the graph system automatically copy the line associated with the train graph copied to this line, At this time the copy of the train graph is not editable, on the basis of this cross-line train graph, the system automatically or manually edit the train graph, and after the collision check storage to the server, and then complete the other lines of the train graph of the edit.

If you need to change the cross-line data in the single line diagram, you need to adjust the cross-line train graph, and then automatically or manually adjust the train graph of the lines.

\section{Summary}

At present, the major cities in China are promoting the subway signaling system interconnection technology, the most important interconnection technology is the cross-line operation; network-line train graph technology will replace the existing the single editing train graph Technology. Cross-line operation is through the establishment of a safe, efficient, systematic operation and management system, the overall arrangement of existing resources, unified coordination between the line and network relations, the realization of line, network effective, safe and reliable operation to achieve network operation of social benefits, economic benefits to maximize.

In summary, this paper expounds the principle of editing the cross-line train graph, comprehensively considers the various elements of editing the cross-line train graph, and probes into the drawing of the cross-line train graph with the example, and the cross-line train graph technology can improve the running efficiency and more reasonable and efficient on the basis of the conventional single train graph. Through the popularization of this technology, it is helpful to reduce the number of passengers transfer and improve operation efficiency.

\section{Acknowledgements}

Beijing Science and Technology Commission project "The research and demonstration of Beijing subway network operation train graph and vehicle signal equipment (D161100004816001)"provides funding.

\section{References}

[1] Slli Jungang,zhou Feng,Zhu Wei,Xu Ruihua,Estimation method of passenger route choice proportion in urban ran transit based on AFC data,JOURNAL OF SOUTHEAST UNIVERSITY(Namral Science Edition),1001—0505(2015)01-0184-05 
[2] LIN Zhan, JIANG Ming qing, LIU Jian feng, SI Bing feng, Improved Logit M odel and M ethod for Urban Rail Transit Network Assignment, Journal of Transportation Systems Engineering and Information Technology, 001-4632(2015)01-0126-07

[3] BAI Li,Urban Rail Transit Norm al and Abnorm al Short. Term Passenger Flow Forecasting M ethod, Journal of Transportation Systems Engineering and Information Technology, 1009-6744(2017)01-0127-09 